Projeção retal de intussuscepção íleo-ceco-cólica em cão Relato de caso

\title{
Rectal projection of ileo-colic intussusception in a dog - Case report
}

\begin{abstract}
Resumo
As intussuscepções intestinais e os prolapsos retais merecem especial atenção e cuidados pois apresentam elevada ocorrência na clínica cirúrgica e necessitam de intervenção urgente. Intussuscepções íleo-ceco-cólicas prolapsadas na via retal não são tão comumente vistas no dia a dia ambulatorial e o seu diagnóstico é realizado com o intuito de ser efetuada a sua diferenciação de prolapso retal simples, que não compromete grandes segmentos intestinais e normalmente não requer celiotomia para a sua redução cirúrgica. $\mathrm{O}$ exame pelo toque retal se faz necessário para a verificação da diferença com o prolapso retal, em vista de que no prolapso retal simples não é permitido ao termômetro ou à sonda projetar-se entre o prolapso e o ânus. Este relato apresenta aspectos relativos à intussuscepção íleo-ceco-cólica prolapsada via retal em animal da espécie canina.
\end{abstract}

\section{Abstract}

Intestinal intussusceptions and rectal prolapses deserve due attention and care because they have a high occurrence in the surgical clinic and require urgent intervention. Rectal prolapsed ileocecal intussusceptions are not so commonly seen on an outpatient basis and diagnosis is made to differentiate from simple rectal prolapses that does not compromise large intestinal segments and does not usually require celiotomy for its surgical reduction. Rectal examination is necessary in order to verify the difference here, since in simple rectal prolapse the thermometer or probe is not allowed to project between the prolapse and the anus. This report aims to present aspects related to rectal prolapsed ileo-cecal colic intussusception in canine species. 


\section{Palavras-chave}

Prolapso intestinal. Intussuscepção. Cão.

Enteroanastomose.

\section{Keywords}

Rectal prolapse. Intussusception. Dog.

Enteroanastomosis.

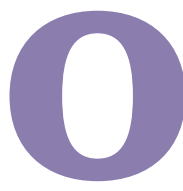

prolapso retal geralmente ocorre secundário à enterite ou à colite em animais jovens (NELSON; COUTO, 2015). No entanto, qualquer afecção que cause tenesmo pode resultar em prolapso retal. A distensão intestinal começa a se formar por causa da irritação retal e, eventualmente, uma parte ou toda a mucosa retal sofre prolapso (NELSON; COUTO, 2015). O prolapso retal completo envolve todas as camadas da parede retal em circunferência total. A quantidade de eversão aumenta com o esforço continuado, variando de alguns milímetros a muitos centímetros. O tecido torna-se edematoso, impedindo a retração espontânea. A exposição continuada causa escoriação, sangramento, ressecamento e necrose.

A intussuscepção é a invaginação de um segmento intestinal (intussuscepto) no interior do lúmen de um segmento adjacente (intussuscepiente) (Figura 1). 


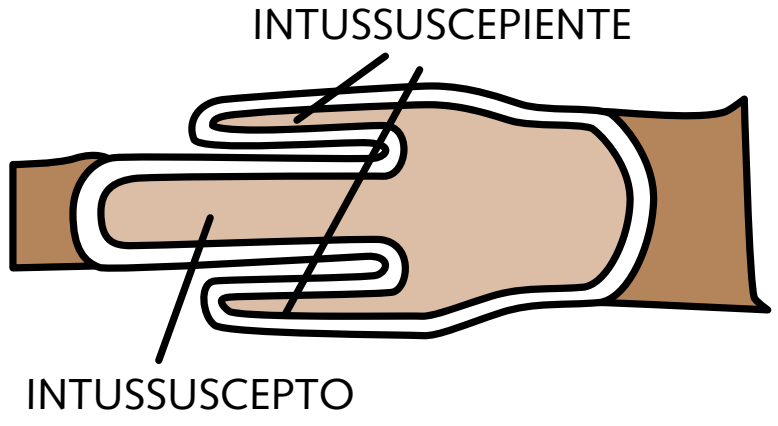

Figura 1 - Esquema de intussuscepção. Fonte: Hedlund e Fossum (2002)

As intussuscepções são associadas frequentemente com enterites (parasitismo, infecções virais ou bacterianas, corpos estranhos e alterações dietéticas) ou enfermidades sistêmicas (HEDLUND; FOSSUM, 2002). Comumente, ocorrem em segmentos jejunais, mas podem ocorrer em qualquer outro ponto do intestino, como a região de transição íleo-ceco-cólica. A direção da intussuscepção pode ser de proximal a distal ou vice- versa. Inicialmente, a invaginação produz a obstrução intestinal parcial, que pode progredir para obstrução completa (HEDLUND; FOSSUM, 2002).

Intussuscepção do ceco no cólon é anormal e inicialmente pode ocorrer de forma intermitente. No entanto, em última instância, o ceco ficará preso pelo esfíncter no orifício cecoico. O comprometimento da drenagem venosa leva então ao esvaziamento da mucosa e sangramento intraluminal. A diarreia não é um achado consistente, mas sangue fresco e coágulos podem ser vistos parcialmente misturados com fezes. Os cães podem apresentar sinais de desconforto abdominal e as intussuscepções podem ser palpáveis. A infestação por Trichuris sp é reivindicada para predispor cães para essa condição, mas também pode ser vista neles após diarreia devido a outras causas (ETTINGER; FELDMAN; CÔTÉ, 2017).

A presença do prolapso intestinal atrai atenção do proprietário e pode facilitar o diagnóstico imediato da afecção. Entretanto, a não diferenciação entre prolapso retal verdadeiro e intussuscepção intestinal prolapsada pode comprometer a vida do paciente. Em se tratando de intussuscepção prolapsada, o tratamento correto inclui intervenção cirúrgica para a correção intra-abdominal da afecção e não apenas a reintrodução do segmento exteriorizado e confecção de bolsa de tabaco. Se isso ocorrer, a manutenção do segmento invaginado irá levar ao quadro de isquemia prolongada, necrose ou ruptura intestinal, seguido de choque séptico e óbito (OLIVEIRA-BARROS; MATERA, 2009b).
O exame retal é necessário para permitir a diferenciação entre prolapso retal e intussuscepção intestinal que se projeta do reto (NELSON; COUTO, 2015). No caso da segunda, é possível a inserção de sonda lisa ou termômetro no espaço existente entre o esfíncter anal externo e a massa entérica prolapsada (HEDLUND; FOSSUM, 2002). O tratamento de escolha ainda é o cirúrgico, com técnicas de redução manual, ressecção da porção acometida associada à enteroanastomose e ao uso de enteroplicações (OLIVEIRA-BARROS; MATERA, 2009b).

\section{Descrição do caso}

Um filhote da espécie canina, da raça Rottweiler, macho, com idade aproximada de três meses, proveniente de São Paulo, foi atendido no Hospital Alpri Vet Premium com relato de prolapso intestinal. Durante a avaliação clínica, foi reportado que o animal fora adquirido há cerca de três dias pelo proprietário proveniente de um canil e que ele, desde que foi levado para sua residência, apresentava fezes pastosas e diarreicas. O cão estava magro (escore corporal 2), alimentava-se pouco, apresentava mucosas róseas, tempo de preenchimento capilar (TPC) de três segundos, com ligeira desidratação (cerca de 2\%), ausência de vômito, opacidade do pelame e linfonodos normais. Segundo relato do proprietário, o animal fora vermifugado pelo canil recentemente, faltando apenas iniciar o protocolo de vacinação. Ele não apresentava ectoparasitas no momento da consulta. O proprietário ainda relatou que foi orientado pelo canil a tratar a diarreia do animal com probiótico veterinário e Giardicid ${ }^{\oplus}$, o qual vinha administrando ao animal tais medicamentos. Questionado, o proprietário relatou que o prolapso ocorrera horas antes (a cerca de 12 horas) do atendimento veterinário.

Pela palpação abdominal, o cão não apresentou dor evidente, porém notou-se "vazio" no abdômen na região ventral. O prolapso apresentava consistência firme, úmida, edematoso, de coloração vermelha escura, com algumas áreas desvitalizadas em sua porção mais distal (Figura 2).

Havia sujidades aderidas em suas paredes, porém não apresentava descamação da mucosa intestinal. Após exames preliminares (hemograma e função renal), com autorização do proprietário, procedeu-se fluidoterapia com soro ringer lactato $(\mathrm{ml} / \mathrm{h})$ e foi efetuada a sedação do animal com o emprego de acepromazina $0,02 \mathrm{mg} /$ $\mathrm{kg}$ intramuscular. Após cinco minutos, aplicou-se, via intravenosa, a associação de xilazina na dose $1,1 \mathrm{mg} / \mathrm{kg}$ e ketamina, $0,05 \mathrm{mg} / \mathrm{kg}$, sendo a metade desta associação administrada lentamente. 


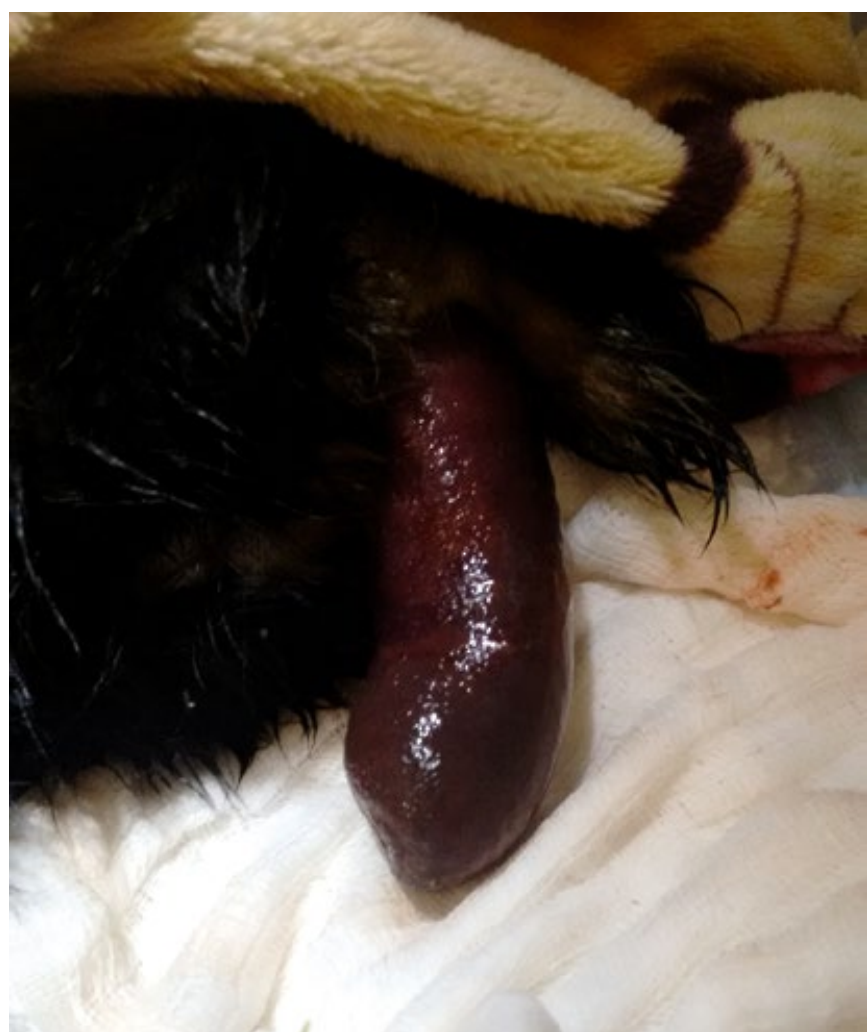

Figura 2 - Imagem fotográfica mostrando prolapso retal de um cão no momento da consulta, na qual pode-se observar o tecido edemaciado, de coloração vermelha escura, apresentado áreas desvitalizadas.

Fonte: Arquivo pessoal (2017)

Uma vez sedado e com perda do reflexo anal, o prolapso foi limpo com solução fisiológica fria e foi sendo revertido e recolocado em sua posição anatômica por compressão com uma compressa cirúrgica úmida. Após este procedimento, o animal foi submetido à palpação abdominal e pôde-se verificar que havia, dorsalmente à vesícula urinária, uma massa espessa que correspondia ao conteúdo prolapsado. $\mathrm{O}$ animal foi internado para monitoração, uma vez que poderia haver novo prolapso, e para exame ultrassonográfico a fim de ser confirmada a suspeita de intussuscepção intestinal. Durante o período de internação, o segmento intussusceptado foi prolapsado novamente. Diante desse quadro, optou-se por não sedar novamente o animal e manter-se o segmento prolapsado e hidratado com soro fisiológico até a realização do exame ultrassonográfico. Após confirmação da suspeita, o animal foi encaminhado para intervenção cirúrgica para redução da intussuscepção e enterectomia do segmento intussusceptado e, posteriormente, para a enteroanastomose.

O paciente foi anestesiado utilizando cloridrato de tramadol na dose de $3 \mathrm{mg} / \mathrm{kg}$ como medicação pré-anestésica (MPA), sendo induzido com propofol na dose de $3 \mathrm{mg} / \mathrm{kg}$ e diazepam na dose de $0,5 \mathrm{mg} / \mathrm{kg}$, via intravenosa e manutenção com anestésico inalatório isoflurano. O posicionamento foi realizado em decúbito dorsal, levemente inclinado cranialmente a cerca de 15 graus, para uma celiotomia na linha mediana ventral. Após exploração do abdômen e visualização da intussuscepção, o prolapso foi cuidadosamente revertido à sua posição anatômica e a porção intestinal acometida foi isolada e exteriorizada com compressas cirúrgicas umidificadas com solução fisiológica (Figura 3).

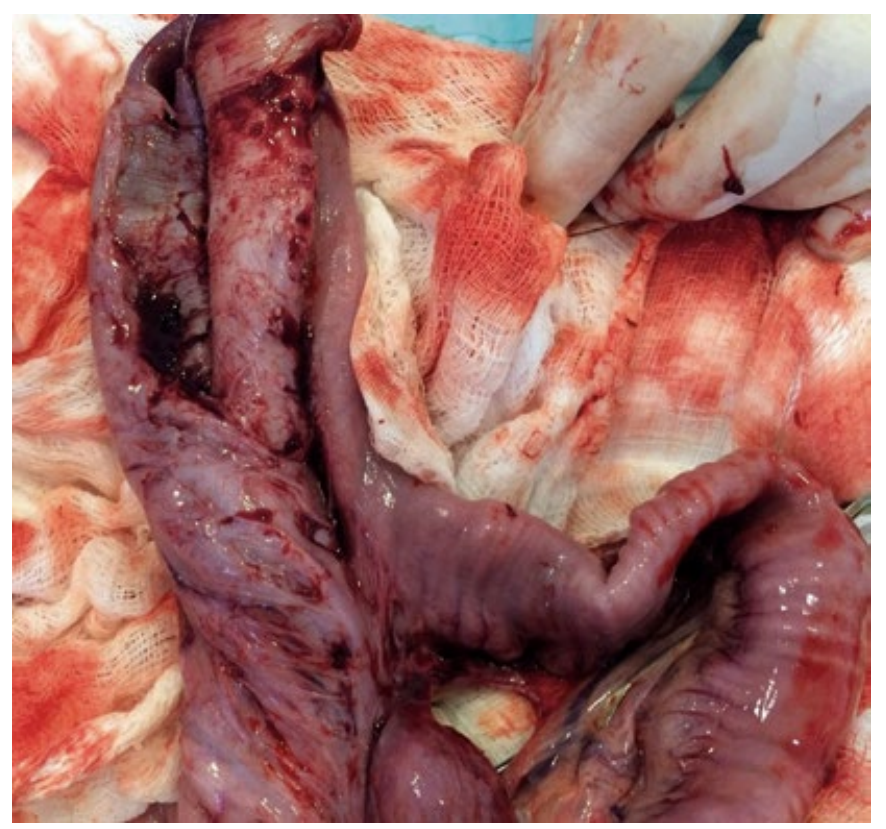

Figura 3 - Intussuscepto íleo-ceco-cólico. Nota-se na imagem porção do intussuscepto íleo-ceco-cólica após redução manual da intussuscepção. Observa-se a alça intestinal com aderências e fibrose.

Fonte: Arquivo pessoal (2017)

Manualmente e com bastante cuidado para não haver rompimento da alça, a intussuscepção foi desfeita por meio de tração sobre sua base ao mesmo tempo em que se deslocava ventralmente o cólon descendente. Uma vez desfeita a intussuscepção, a área afetada foi ressectada (Figura 4) e procedeu-se então à enteroanastomose jejuno-cólico terminal utilizando fio de sutura absorvível Procare ${ }^{\circledast}$ (ácido poliglicólico - PGA) 4-0 monofilamentoso.

Após reposicionamento do intestino na cavidade abdominal, foi efetuada a sutura da musculatura com fio inabsorvível nylon 2-0 e, posteriormente, da derme com o mesmo material. O paciente foi mantido em regime de internação (Figura 5) durante 72 horas para monitoração e tratamento. Foi prescrito metronidazol, na dose de $15 \mathrm{mg} /$ $\mathrm{kg}$ BID, via intravenosa; ceftriaxona, na dose $25 \mathrm{mg} / \mathrm{kg}$ BID, via intravenosa; cloridrato de ranitidina, na dose de $1 \mathrm{mg} /$ $\mathrm{kg}$ BID, via subcutânea; cloridrato de tramadol, $1 \mathrm{mg} / \mathrm{kg}$ TID, via subcutânea; e maxican $0,2 \%$, na dose de $0,1 \mathrm{mg} /$ kg SID, via subcutânea. Após nova ultrassonografia, foi 
dada alta ao animal. A retirada de pontos ocorreu dez dias após o procedimento cirúrgico. A alimentação foi administrada após oito horas do procedimento cirúrgico de forma líquida/pastosa durante os três dias de internação e, depois, foi prescrita a volta da alimentação normal após o quinto dia do pós-operatório.

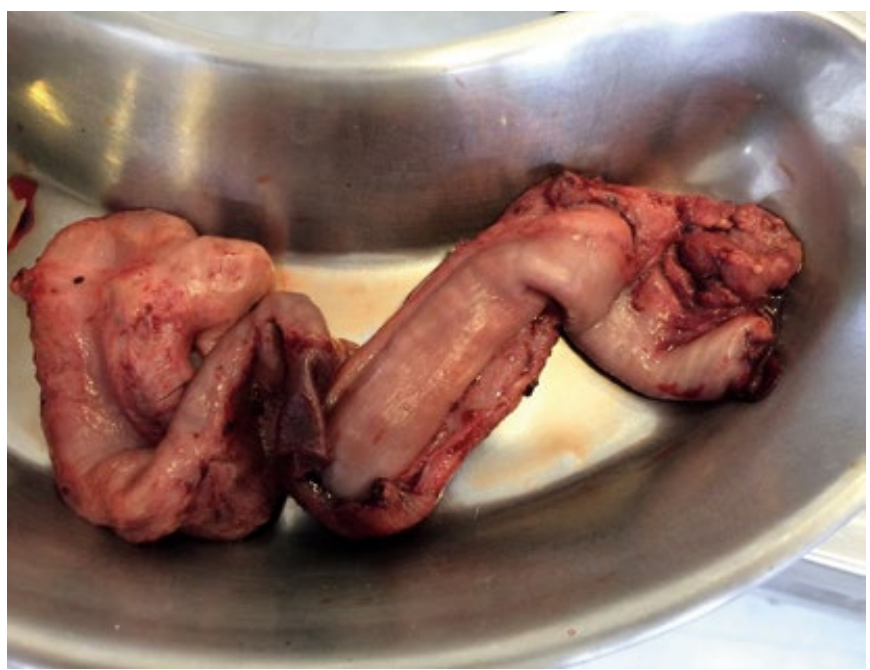

Figura 4 - Porção ressectada correspondente a região íleo-ceco-cólica. Fonte: Arquivo pessoal (2017).

\section{Discussão}

Qualquer afecção que cause tenesmo pode resultar em um prolapso retal. A distensão começa a se formar por causa da irritação retal e, eventualmente, uma parte ou toda a mucosa retal sofre prolapso (NELSON; COUTO, 2015). O prolapso retal completo envolve todas as camadas da parede retal e a circunferência inteira. A quantidade de eversão aumenta com o esforço continuado, variando de alguns milímetros a muitos centímetros de segmento prolapsado. $\mathrm{O}$ tecido fica edematoso, impedindo a retração espontânea. A exposição continuada causa escoriação, sangramento, ressecamento e necrose (HEDLUND; FOSSUM, 2002). A presença do prolapso intestinal atrai atenção do proprietário e pode facilitar o diagnóstico imediato da afecção (OLIVEIRABARROS; MATERA, 2009a). Durante a anamnese - e por ser evidente o prolapso intestinal com sua mucosa de coloração escura e edematosa, algumas escoriações, queixa de diarreia e parasitismo recente - pensou-se apenas como diagnóstico o prolapso intestinal. Mas, com a evolução do exame físico e após a redução do segmento prolapsado, ficou evidente que havia outra afecção envolvida.

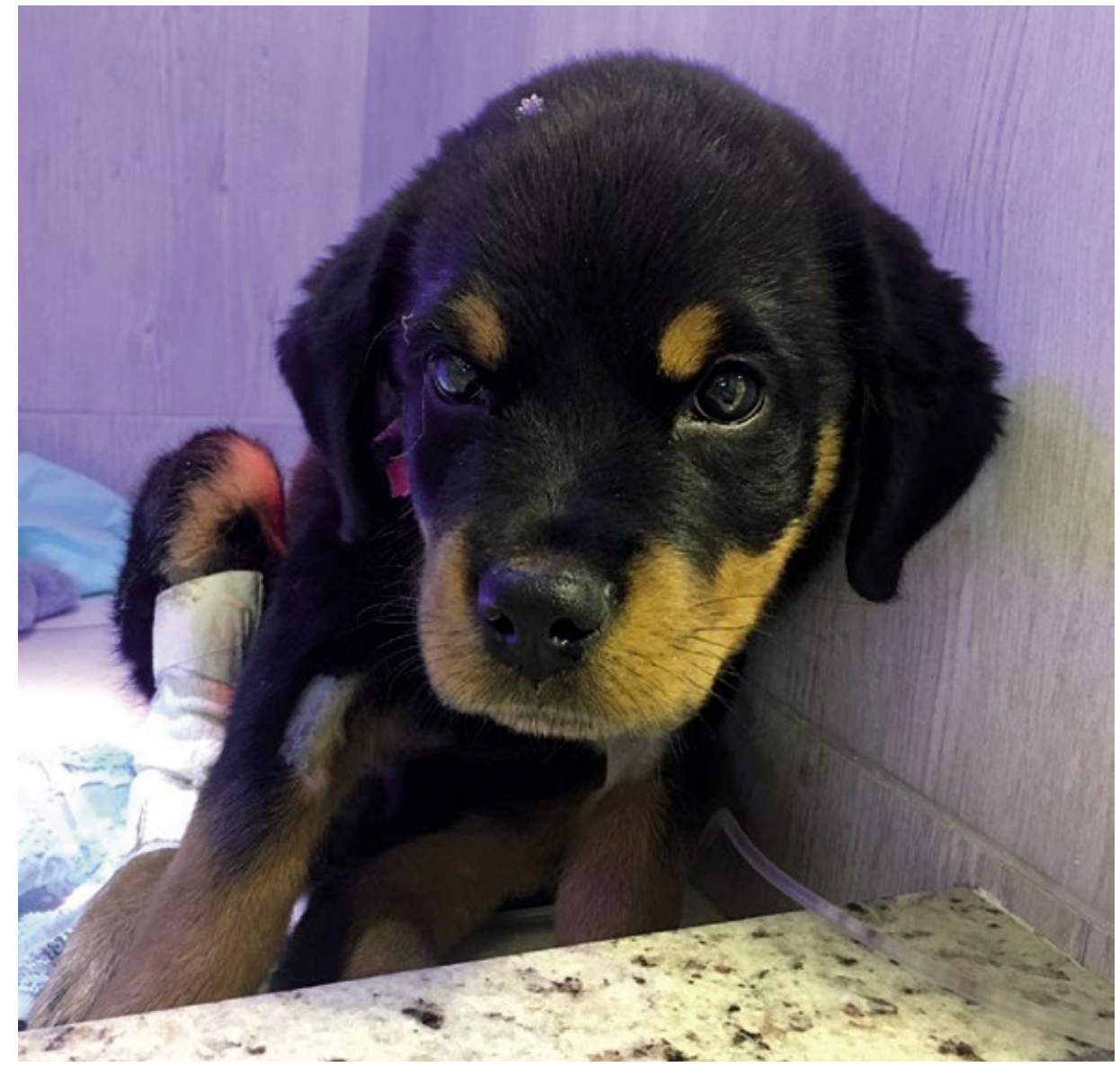

Figura 5 - Paciente em regime de internação no pós-cirúrgico imediato. Fonte: Arquivo pessoal (2017). 
A intussuscepção intestinal é mais frequente em animais jovens e geralmente é causada por hipermotilidade secundária à enterite ou ao parasitismo (TANGNER, 1982). O exsudato fibrinoso da serosa causa a aderência das camadas invaginadas, dificultando a sua redução, e a manutenção do segmento invaginado levará ao quadro de isquemia prolongada, necrose, ruptura intestinal, seguido de choque séptico e óbito (TANGNER, 1982; OLIVEIRA-BARROS; MATERA, 2009a). Por se tratar de um filhote adquirido recentemente de um canil e por ele apresentar diarreia, tendo como suspeita parasitismo, e ainda, após redução do segmento prolapsado, na palpação abdominal ser evidente uma "massa" em região de colón descendente, foi levantada a hipótese de que se tratava de uma intussuscepção intestinal que, devido ao tenesmo, evoluiu para um prolapso intestinal. Devido a esta suspeita, foi solicitada uma ultrassonografia para a confirmação diagnóstica da intussuscepção.

A não diferenciação entre prolapso retal verdadeiro e intussuscepção prolapsada pode comprometer a vida do paciente. Em se tratando de intussuscepção prolapsada, o tratamento correto inclui intervenção cirúrgica para correção intra-abdominal da afecção e não apenas a reintrodução do segmento exteriorizado. Se isso ocorrer, a manutenção do segmento invaginado irá levar ao quadro de isquemia prolongada, necrose ou ruptura intestinal, seguido de choque séptico e óbito (OLIVEIRA-BARROS; MATERA, 2009b). Uma vez diagnosticada a intussuscepção como causadora do prolapso intestinal, o paciente foi encaminhado à cirurgia.

\section{Conclusão}

Nos casos em que animais de pouca idade apresentarem prolapsos retais ou intestinais, deverá ser efetuada a diferenciação entre prolapso e intussuscepção prolapsada, visto que os sinais clínicos, principalmente os visuais, podem gerar confusão e o diagnóstico impreciso pode comprometer a vida do paciente e levá-lo a óbito.

\section{Referências}

ETTINGER, S. J.; FELDMAN, E. C.; CÔTÉ, E. (Ed.). Textbook of veterinary internal medicine. 8. ed. St. Louis: Elsevier, 2017. 5875p. 2 vol.

HEDLUND, C. S.; FOSSUM, T. W. Cirurgia do sistema digestório. In: FOSSUM, T. W. Cirurgia de pequenos animais. 1. ed. São Paulo: Mosby Elsevier, 2002. p. 344-347.

NELSON, R. W.; COUTO, C. G. Medicina interna de pequenos animais. 5. ed. Rio de Janeiro: Elsevier, 2015. 1512 p.

OLIVEIRA-BARROS, L. M.; MATERA, J. M. Estudo retrospectivo das intussuscepções em cães. Brazilian Journal Veterinary Research and Animal Science, São Paulo, v. 46, n. 5, p. 370-377, 2009a.

Intussuscepção em cães: revisão de literatura. Revista

Acadêmica: Ciências Agrárias e Ambientais, Curitiba, v. 7, n. 3 p. $265-272,2009$ b.

TANGNER, C. H. A review of canine intestinal intussusception. The Southwestern Veterinarian, College Station, v. 34, n. 3, p. $203-$ 206, 1982. 